\title{
Progress in mechanisms of acetylcholinesterase inhibitors and memantine for the treatment of Alzheimer's disease
}

\author{
Shao-Min Li' ${ }^{1}$ Ming-Shu Mo², Ping-Yi Xu ${ }^{2}$ \\ ${ }^{1}$ Center for Neurologic Disease, Department of Neurology, Brigham and Women's Hospital, Harvard Medical School, Boston, \\ Massachusetts 02115, USA. \\ ${ }^{2}$ Department of Neurology, The First Affiliated Hospital of Sun Yat-Sen University, Guangzhou 510080, Guangdong, China.
}

\section{A B S T R A C T}

Alzheimer's disease (AD) is the most common causes of dementia in the elderly. Currently, only two classes of drugs, acetylcholinesterase inhibitors (AChEls) and memantine are approved. AChEls ameliorate cognitive and psychiatric symptoms in $A D$ patients through activation of acetylcholine ( $A C h)$ receptors by increased synaptic ACh levels and also have protective effects against glutamate neurotoxicity and inflammation, whereas memantine appears to mainly protect against excitotoxicity and neurodegeneration. Herein, we review the pharmacologic properties of the available AChEls and memantine, and focus on recent progress in the mechanisms of $A D$ in relation to acetylcholinergic and glutamatergic involvement.

Key words: Alzheimer's disease, amyloid- $\beta$ peptide, donepezil, memantine, tau

\section{INTRODUCTION}

As the world's population ages and life expectancy increases, many individuals are faced with an increased risk of developing dementia. The most common form of dementia is Alzheimer's disease (AD). About 35.6 million people worldwide are now suffering from $\mathrm{AD}$, and the disease is expected to affect 115 million by 2050. ${ }^{[1]}$ Although this disease has been known about for over a century, there is no curative treatment available so far. At present, four drugs have been approved by the United States Food and Drug Administration for the symptomatic treatment of AD. The acetylcholinesterase (AChE) inhibitors donepezil, rivastigmine, and galantamine are suggested for managing mild-to-moderate $\mathrm{AD}$, whereas donepezil and memantine, a

Corresponding Author: Prof. Ping-Yi Xu,

Department of Neurology, The First Affiliated Hospital of Sun Yat-Sen University, No. 58, Zhongshan 2nd Road,

Guangzhou 510080, Guangdong, China.

E-mail: pingyixujd@163.com

\begin{tabular}{|l|l|}
\hline \multicolumn{2}{|c|}{ Access this article online } \\
\hline Quick Response Code: & \\
\hline & Website: \\
\hline & www.nnjournal.net \\
\cline { 2 - 3 } & DOI: \\
\hline
\end{tabular}

noncompetitive antagonist of N-methyl-D-aspartate receptors (NMDAR), is indicated for patients with moderate or severe AD. ${ }^{[1-3]}$

Pathologically, AD is characterized by atrophy of the hippocampus and neocortex resulting from neuronal and synaptic loss, and the deposition of two proteinaceous lesions: senile plaques containing a core of amyloid-beta $(\mathrm{A} \beta)$ peptide and neurofibrillary tangles (NFT) composed of hyperphosphorylated microtubule-associated tau protein. ${ }^{[3,4]}$ It is well-accepted that the accumulation of $A \beta$ protein plays a central role in the pathogenesis of $\mathrm{AD}$. The severity of dementia in $\mathrm{AD}$ correlates more strong with cortical levels of soluble $\mathrm{A} \beta$ species than with insoluble amyloid plaque burden ${ }^{[5,6]}$ Experimentally, soluble $\mathrm{A} \beta$ oligomers have been specifically shown to block hippocampal long-term potentiation (LTP), an electrophysiological correlate of learning and memory, in vivo and in brain slices. ${ }^{[-9]}$ Understanding precisely how $\mathrm{A} \beta$ impairs hippocampal synaptic function could enable the development of potential therapeutics for $\mathrm{AD}$.

This is an open access article distributed under the terms of the Creative Commons Attribution-NonCommercial-ShareAlike 3.0 License, which allows others to remix, tweak, and build upon the work non-commercially, as long as the author is credited and the new creations are licensed under the identical terms. For reprints contact: nn_editor001@nnjournal.net

Cite this article as: Li SM, Mo MS, Xu PY. Progress in mechanisms of acetylcholinesterase inhibitors and memantine for the treatment of Alzheimer's disease. Neuroimmunol Neuroinflammation 2015;2:274-80.

Received: 14-03-2015; Accepted: 29-07-2015 
Synaptic loss is one of the pathological hallmarks of AD and the best correlate of cognitive decline ${ }^{[10,11]}$ suggesting that it is a critical event in the pathophysiology of the disease. Several factors such as $A \beta$ production, cholinergic dysfunction, NFT accumulation, inflammatory agents, oxidative stress, mitochondrial dysfunction, glutamate-mediated excitotoxicity, and genetic components are reported to be involved in the pathogenesis. ${ }^{[3]}$ Proposed explanations for the pathophysiology of $\mathrm{AD}$ include the cholinergic hypothesis ${ }^{[11]}$ the soluble $\mathrm{A} \beta$ oligomers hypothesis, ${ }^{[12]}$ and the tau hypothesis. ${ }^{[12,13]}$

\section{CHOLINERGIC SYSTEM}

Acetylcholine (ACh) is widely distributed in the nervous system and plays a critical role in cerebral cortical development, cortical activity, and learning and memory processes. Cholinergic neurons in the brainstem and basal forebrain project axons to many areas of the brain. All functions of the cholinergic system are controlled by the interaction of ACh with two families of receptors: muscarinic ACh receptors (mAChRs) and nicotinic ACh receptors (nAChRs). ${ }^{[14]}$

Hippocampal cholinergic activity contributes to memory Many studies have shown that hippocampal-dependent learning is associated with an increase in hippocampal ACh levels; thus, the elevation of extracellular ACh is thought to reflect hippocampal-dependent memory processes. ${ }^{[15]}$ Several behavioral studies have demonstrated that lesion-induced damage to cholinergic activity in the basal forebrain and its projections to the neocortex induced learning and memory deficits. ${ }^{[16]}$ Pharmacological experiments have further confirmed that cholinergic receptor agonists and acetylcholinesterase inhibitors (AChEIs) reduce the severity of cognitive dysfunction, ${ }^{[17]}$ whereas anticholinergic drugs cause learning and memory deficits in both animal and humans. ${ }^{[18]}$ Antagonists of mAChRs such as scopolamine, impair the encoding of new memories in animal models of learning and memory and produce cognitive impairment in humans. ${ }^{[15]}$

It has been found that pharmacological activation of mAChRs or nAChRs produces an LTP-like increase in synaptic transmission in the hippocampal CA1 region. ${ }^{[14]}$ Blockade of the presynaptic inhibitory M2/M4 subtype of mAChRs by methoctramine increased ACh levels, and elicited a pharmacological LTP ${ }^{[19]}$ that shares a similar mechanism with tetanus-induced LTP. ${ }^{[20]}$ In accordance, both the endogenous release of ACh in vivo and the exogenous application of mAChR agonists in vitro facilitate the induction of LTP. ${ }^{[14]}$ Increasing endogenously released ACh specifically activates the nAChR, facilitating LTP induction. ${ }^{[21]}$ Selective depletion of medial septum cholinergic neurons caused LTP impairment and glutamatergic synaptic current alteration in the hippocampus. ${ }^{[22]}$

\section{Glutamatergic effect}

The facilitation of LTP by mAChR activation is thought to be mediated by enhancement of synaptic NMDAR activity either by direct alteration of NMDAR channels ${ }^{[14]}$ or by induction of $\mathrm{Ca}^{2+}$ release from endoplasmic reticulum stores. ${ }^{[23]}$ The $\mathrm{mAChRs}$ also inhibit a variety of potassium channels including small conductance calcium-activated KCa2 channels (SK channels). ${ }^{[24]}$ Therefore, mAChR activation might induce a parallel long-term enhancement of both $\alpha$-amino-3-hydrox y-5-methyl-4-isoxazolepropionic acid (AMPA) and NMDAR-mediated transmission. ${ }^{[25]}$

It has been reported that chronic nicotine administration and in vitro acute nicotine treatment increases ACh release and enhances NMDAR responses in the hippocampus. ${ }^{[26]}$ One potential mechanism is that nicotine acts at presynaptic nAChRs to increase glutamate release onto postsynaptic NMDARs. ${ }^{[27]}$ The activation of nAChRs causes $\mathrm{Ca}^{2+}$ entry through receptor channels, which can trigger $\mathrm{Ca}^{2+}$ release from intracellular stores. ${ }^{[28]}$ Multiple lines of evidence also suggest that nicotine could act to ameliorate hippocampal-based learning deficits associated with changes in NMDAR function. ${ }^{[29]}$ Consistent with these studies, pretreatment with AChE inhibitors has been found to protect cortical neurons from glutamate neurotoxicity in a time- and dose-dependent manner through activation of nAChR. ${ }^{[30]}$

\section{Anti-inflammatory effect}

The deposition of $A \beta$ is the result of an imbalance between $A \beta$ production and clearance. This imbalance leads to a situation of chronic inflammation in the brain. $A \beta$ deposition contributes to the activation of astrocytes and microglia, and induces the production of a series of proinflammatory cytokines, chemokines, macrophage inflammatory proteins, leukotrienes, reactive oxygen species, and nitric oxide (NO)..$^{[3,31,32]}$ The neuroinflammatory cytokines may not only contribute to neuronal death, but they might also influence classical neurodegenerative pathways such as amyloid precursor protein (APP) processing and tau phosphorylation.

A growing body of studies using donepezil has shown that donepezil does not function solely at the level of ACh, but also has potent anti-inflammatory effects in $\mathrm{AD}$ patients, a tauopathy mouse model and lipopolysaccharide (LPS)-treated animals. ${ }^{[33]}$ Donepezil inhibits proinflammatory gene expression directly 
resulting in reduced secretion of tumor necrosis factor-alpha, NO, and interleukin-1 beta in LPS-treated BV2 cells, a murine microglia cell line.$^{[34]}$ Furthermore, donepezil may inhibit neuronal death and cognitive decline by repressing oligomeric $A \beta$-triggered inflammatory pathways in microglia. ${ }^{[35]}$ Thus, donepezil-mediated attenuation of the release of inflammatory mediators may result from inhibition of protein expression of proinflammatory molecules.

The cholinergic pathway has been shown to exert anti-inflammatory effects on several diseases such as rheumatoid arthritis, ${ }^{[36]}$ inflammatory bowel disease, ${ }^{[37]}$ sepsis, ${ }^{[38]}$ and cardiovascular diseases. ${ }^{[39]}$ On the other hand, nAChR has been shown to possess anti-inflammatory properties in macrophages, ${ }^{[40]}$ and the activation of $\alpha 7-n A C h R$ significantly inhibits the production of proinflammatory cytokines. ${ }^{[41]}$ It has been demonstrated that AChEI treatment may favor a Th2-mediated immune response by activating B-lymphocytes and increasing immunoglobulin production. ${ }^{[42]}$ Galantamine-enhanced microglial $\mathrm{A} \beta$ phagocytosis to promote $A \beta$ clearance requires the combined action of an ACh competitive agonist and the allosterically potentiating ligand for nAChRs. ${ }^{[43]}$ Furthermore, plasma anti-A $\beta_{1-42}$ antibody levels in $\mathrm{AD}$ patients were found to be significantly increased after AChEI treatment, ${ }^{[44]}$ thus suggesting that increasing the endogenous response against $A \beta$ might provide new insights for AD therapy. Recently, several promising studies have been conducted in phase II and phase III trials using active and passive immunotherapies, respectively. ${ }^{[45]}$

\section{GLUTAMATERGIC SYSTEM}

Glutamate is one of the most prominent neurotransmitters in the body. It is present in over 50\% of the nervous tissue. ${ }^{[46]}$ It plays a prominent role in a variety of brain functions including synaptic transmission, neuronal growth and differentiation, synaptic plasticity, learning and memory, and other cognitive functions.

The role of the glutamatergic system is to convert nerve impulses into a chemical stimulus by controlling the concentration of glutamate at the synapse. It is well-accepted that LTP induction triggers the NMDAR, and therefore, activates the AMPA receptor in the CA1 region. ${ }^{[47,48]}$ NMDAR activation allows $\mathrm{Ca}^{2+}$ to enter the postsynaptic cell, which subsequently triggers a number of kinase pathways and increases protein transcription. This process strengthens synapses and increases synaptic density, thus allowing fast adaptations of network activity which are critical for information processing. ${ }^{[49]}$

\section{Neuroexcitotoxicity}

Glutamate excitotoxicity has been hypothesized to have a role in $\mathrm{AD}$ pathogenesis. Dysfunction of glutamate transporters has been implicated in this pathway. ${ }^{[50]} \mathrm{It}$ has been reported that hippocampal excitatory amino acid transporter 1 (EAAT1) and EAAT2 expression is significantly reduced in $\mathrm{AD},{ }^{[49]}$ further reinforcing the notion of a deficit in glutamate clearance in $\mathrm{AD}$ brain. In addition to uptake defects, the abnormal release of glutamate from vesicle stores has been implicated as a source of excess extracellular glutamate in AD. ${ }^{[51]}$ Excessive activation of glutamate receptors leads to a number of deleterious consequences including impairment of calcium buffering, generation of free radicals, and activation of the mitochondrial permeability transition that results in release of apoptogenic proteins into the cytosol, where they trigger caspase-dependent apoptosis or promote autophagy. ${ }^{[52]}$

We and others have demonstrated that $A \beta$ inhibits glutamate uptake in rat cortical synaptosomes, cultured cells, and acute brain slices. ${ }^{[9]}$ These findings are also consistent with an intracerebroventricular injection of $\mathrm{A} \beta$ into rat brain, which causes a rapid increase in interstitial fluid glutamate levels without altering gamma-aminobutyric acid or aspartate. ${ }^{[53]}$ The hydrophobic $\mathrm{A} \beta$ oligomers may bind principally to membrane lipids, and thereby, secondarily interrupt the structure and function of synaptic transmembrane transporters (glutamate transporters), leading to increases in extracellular glutamate concentration.

\section{Activation of extrasynaptic receptors}

Electron microscopic studies have shown that most plasmalemma receptors are extrasynaptically located, whereas only $1-2 \%$ of cell membrane receptors are located at synaptic sites in the hippocampus. ${ }^{[54]}$ Thus, the chemicals distribute in the extracellular fluid and bind preferentially to these vastly extrasynaptic receptors. Extrasynaptic NMDARs, that is, receptors that are not activated during low-frequency synaptic events, can be found at various locations, such as the cell body, the dendritic shaft, the neck of the dendritic spine, and adjacent to the postsynaptic density. It has been found that synaptic NMDAR activity is extremely important for neuronal survival, whereas the extrasynaptic NMDARs are coupled to cell death pathways. ${ }^{[55]}$ Using both whole-cell recording and Fluo-4 calcium measurements, we confirmed that $A \beta$ rapidly and significantly increases extrasynaptic NMDA responses. Soluble A $\beta$ oligomers activate extrasynaptic NR2B-containing NMDARs, thus increasing downstream calpain signaling and p38 mitogen-activated protein kinase activity. ${ }^{[9]}$ Several studies have demonstrated that selective 
NR2R antagonists prevent $A \beta$-induced synaptic dysfunction. ${ }^{[9]}$ Consistent with these findings, low concentrations of memantine have been shown to target extrasynaptic NMDAR. ${ }^{[56]}$ Both studies and related reports suggest that $A \beta$ oligomers disrupt glutamate uptake or trigger glutamate release from glial cells, thus increasing glutamate levels to induce synaptic dysfunction.

\section{BEHAVIORAL AND PSYCHOLOGICAL SYMPTOMS IN DEMENTIA}

$\mathrm{AD}$ is a neurodegenerative disorder associated not only with a decline in cognitive abilities, but also with frequent manifestation of noncognitive symptoms (such as anxiety, depression, apathy, and psychosis) and other conduct disorders that impair daily living. ${ }^{[57]}$ It has been proposed that the behavioral and psychological symptoms of dementia in $\mathrm{AD}$ patients are due to an imbalance of different neurotransmitters (ACh, dopamine, noradrenaline, and serotonin) in specific brain regions responsible for emotional activities (parahippocampal gyrus, dorsal raphe, and locus coeruleus) and cortical hypometabolism. ${ }^{[58]}$

There is increasing awareness that the cholinergic system plays a role in emotion and noncognitive behavior and may be involved in neuropsychiatric symptoms of $\mathrm{AD} .^{[59,60]}$ Other evidence indicates that monoamines, in addition to ACh, are also involved in the pathogenesis of $\mathrm{AD}$ and other dementia disorders. The increased activity and altered serotonergic modulation as a result of dopaminergic neurotransmission are associated with agitated and aggressive behavior, respectively. ${ }^{[61]}$ Chronic administration of donepezil has been reported to reduce the incidence of neuropsychiatric symptoms in patients with mild to moderately severe AD. ${ }^{[62]}$ Thus, the stimulation of monoaminergic activity in conjunction with AChE activity may provide an effective treatment option for AD and accompanying psychiatric disorders.

\section{COMPARISON OF DONEPEZIL AND MEMANTINE}

It is well-established that AChEIs inhibit the action of the ACh-hydrolyzing enzyme AChE to boost ACh levels, and thus, alleviate disease symptoms associated with the progressive loss of cholinergic function in $\mathrm{AD}$. In contrast, memantine acts at the NMDAR to lower the pathologically increased tonic level of excitation of the glutamatergic synapse at rest. Although AChEIs significantly improve learning and memory, memantine behaves like other NMDAR antagonists and has been reported to inhibit hippocampal LTP, ${ }^{[63]}$ disrupt cognitive flexibility, and impair memory and locomotor behaviors. ${ }^{[64,65]}$ Interestingly, a comparison between the effects of donepezil and memantine on spatial memory in the APP23 mouse model using a complex dry-land maze test showed that donepezil treatment significantly improved moving time, whereas memantine improved resting time, thus suggesting that donepezil may influence memory acquisition and memantine influences memory retrieval. ${ }^{[66]}$

Donepezil administration increases dopamine and norepinephrine levels in the dorsal hippocampus and decreases extracellular norepinephrine and serotonin levels in the ventral hippocampus. ${ }^{[67]}$ In contrast, memantine decreases dopamine and serotonin in the dorsal hippocampus and increases 3-methoxy-4-hydrophenylglycol in the ventral hippocampus. Although memantine is recognized as a moderate affinity, noncompetitive, reversible NMDAR antagonist, it has been demonstrated that memantine enhances synaptic transmission in an mAChR-dependent manner in the mouse hippocampus ${ }^{[68]}$ and may interact more potent with cholinergic receptors than with NMDAR. ${ }^{[69]}$ Acute systemic or local administration of either memantine or donepezil significantly increases ACh levels in the neocortex and hippocampus of rats. ${ }^{[0]}$

\section{EFFICACY OF DONEPEZIL AND MEMANTINE ON THE TREATMENT OF AD}

AChEIs are considered the standard treatment of the mild-to-moderate stage of $\mathrm{AD},{ }^{[71]}$ whereas memantine is suggested for moderate-to-severe AD patients. ${ }^{[72]}$ Clinically, donepezil at $10 \mathrm{mg} /$ day significantly improves cognitive, neuropsychiatric, and global function, thus reducing caregiver burden. ${ }^{[62,72]}$ Increasing the daily dose to $23 \mathrm{mg} /$ day was found to be safe and tolerated in patients with moderate-to-severe $\mathrm{AD} \cdot .^{[73,74]}$ Memantine has been found to improve global cognition, functional communication, and some behavioral symptoms (agitation and aggression). ${ }^{[75,76]}$ Interestingly, donepezil and memantine also have differential behavioral effects: donepezil affects depression, anxiety, and apathy whereas memantine mainly affects agitation, aggression, and delusions. ${ }^{[77,78]} \mathrm{A}$ recent clinical review suggests that combination therapy with donepezil and memantine for $\mathrm{AD}$ could be safe and well-tolerated for moderate-to-severe AD. ${ }^{[79]}$ However, there are no significant benefits of the combination of donepezil and memantine over donepezil alone on cognitive function. ${ }^{[80]}$ Thus, combination therapy may be more effective in improving neuropsychiatric behaviors than cognition because of their complementary activity. 


\section{CONCLUSION}

AChE inhibitors ameliorate the cognitive and psychiatric symptoms in $\mathrm{AD}$ patients through increased synaptic ACh levels to activate AChRs and protect against glutamate neurotoxicity and inflammation, whereas memantine appears to mainly protect against excitotoxicity and consequent neurodegeneration. AChE inhibitors exert neuroprotective effects by improving cholinergic mediated memory function, enhancing glutamatergic responses and acting as anti-inflammatory agent. Memantine is efficient at preventing the deleterious actions of $\mathrm{A} \beta$ oligomers mainly due to its selectivity for the extrasynaptic NMDARs. Therefore, AChE inhibitors could be used for the earlier to later stages of $\mathrm{AD}$, but memantine should preferentially be used only in the later phase of $\mathrm{AD}$.

\section{Acknowledgments}

This work was supported by research grants from the State Key Development Program for Basic Research of China (2011CB510000), the National Natural Science Foundation of China (81271428, 81471292, and 81430021), and a grant supported by assisting research project of science and technology for Xinjiang (201591160).

\section{Financial support and sponsorship}

Nil.

\section{Conflicts of interest}

There are no conflicts of interest.

\section{REFERENCES}

1. Alzheimer's A. 2013 Alzheimer's disease facts and figures. Alzheimers Dement 2013;9:208-45.

2. Birks J, Harvey RJ. Donepezil for dementia due to Alzheimer's disease. Cochrane Database Syst Rev 2006;25:CD001190.

3. Querfurth HW, LaFerla FM. Alzheimer's disease. N Engl J Med 2010;362:329-44.

4. Perl DP. Neuropathology of Alzheimer's disease. Mt Sinai $J$ Med 2010;77:32-42.

5. Lue LF, Kuo YM, Roher AE, Brachova L, Shen Y, Sue L, Beach T, Kurth JH, Rydel RE, Rogers J. Soluble amyloid beta peptide concentration as a predictor of synaptic change in Alzheimer's disease. Am J Pathol 1999;155:853-62.

6. McLean CA, Cherny RA, Fraser FW, Fuller SJ, Smith MJ, Beyreuther K, Bush AI, Masters CL. Soluble pool of Abeta amyloid as a determinant of severity of neurodegeneration in Alzheimer's disease. Ann Neurol 1999;46:860-6.

7. Shankar GM, Li S, Mehta TH, Garcia-Munoz A, Shepardson NE, Smith I, Brett FM, Farrell MA, Rowan MJ, Lemere CA, Regan CM, Walsh DM, Sabatini BL, Selkoe DJ. Amyloid-beta protein dimers isolated directly from Alzheimer's brains impair synaptic plasticity and memory. Nat Med 2008;14:837-42.

8. Klyubin I, Ondrejcak T, Hayes J, Cullen WK, Mably AJ, Walsh DM, Rowan MJ. Neurotransmitter receptor and time dependence of the synaptic plasticity disrupting actions of Alzheimer's disease Abeta in vivo. Philos Trans R Soc Lond B Biol Sci 2014;369:20130147.

9. Li S, Jin M, Koeglsperger T, Shepardson NE, Shankar GM, Selkoe DJ. Soluble Abeta oligomers inhibit long-term potentiation through a mechanism involving excessive activation of extrasynaptic NR2B-containing NMDA receptors. J Neurosci 2011;31:6627-38.

10. Terry RD, Masliah E, Salmon DP, Butters N, DeTeresa R, Hill R, Hansen LA, Katzman R. Physical basis of cognitive alterations in Alzheimer's disease: synapse loss is the major correlate of cognitive impairment. Ann Neurol 1991;30:572-80.

11. Contestabile A. The history of the cholinergic hypothesis. Behav Brain Res 2011;221:334-40.

12. Hardy J, Selkoe DJ. The amyloid hypothesis of Alzheimer's disease: progress and problems on the road to therapeutics. Science 2002;297:353-6.

13. Zempel H, Thies E, Mandelkow E, Mandelkow EM. Abeta oligomers cause localized $\mathrm{Ca}(2+)$ elevation, missorting of endogenous Tau into dendrites, Tau phosphorylation, and destruction of microtubules and spines. J Neurosci 2010;30:11938-50.

14. Drever $\mathrm{BD}$, Riedel G, Platt $\mathrm{B}$. The cholinergic system and hippocampal plasticity. Behav Brain Res 2011;221:505-14.

15. Micheau J, Marighetto A. Acetylcholine and memory: a long, complex and chaotic but still living relationship. Behav Brain Res 2011;221:424-9.

16. Schliebs $\mathrm{R}$, Arendt $\mathrm{T}$. The cholinergic system in aging and neuronal degeneration. Behav Brain Res 2011;221:555-63.

17. Hasselmo ME, Sarter M. Modes and models of forebrain cholinergic neuromodulation of cognition. Neuropsychopharmacology 2011;36:52-73.

18. Easton A, Douchamps V, Eacott M, Lever C. A specific role for septohippocampal acetylcholine in memory? Neuropsychologia 2012;50:3156-68.

19. Li S, Cullen WK, Anwyl R, Rowan MJ. Muscarinic acetylcholine receptor-dependent induction of persistent synaptic enhancement in rat hippocampus in vivo. Neuroscience 2007;144:754-61.

20. Hayes J, Li S, Anwyl R, Rowan MJ. A role for protein kinase A and protein kinase $\mathrm{M}$ zeta in muscarinic acetylcholine receptor-initiated persistent synaptic enhancement in rat hippocampus in vivo. Neuroscience 2008;151:604-12.

21. Nakauchi S, Sumikawa K. Endogenously released ACh and exogenous nicotine differentially facilitate long-term potentiation induction in the hippocampal CA1 region of mice. Eur J Neurosci 2012;35:1381-95.

22. Kanju PM, Parameshwaran K, Sims-Robinson C, Uthayathas S, Josephson EM, Rajakumar N, Dhanasekaran M, Suppiramaniam V. Selective cholinergic depletion in medial septum leads to impaired long term potentiation and glutamatergic synaptic currents in the hippocampus. PLoS One 2012;7:e31073.

23. Fernandez de Sevilla D, Nunez A, Borde M, Malinow R, Buno W. Cholinergic-mediated IP3-receptor activation induces long-lasting synaptic enhancement in CA1 pyramidal neurons. $J$ Neurosci 2008;28:1469-78.

24. Buchanan KA, Petrovic MM, Chamberlain SE, Marrion NV Mellor JR. Facilitation of long-term potentiation by muscarinic $\mathrm{M}(1)$ receptors is mediated by inhibition of SK channels. Neuron 2010;68:948-63.

25. Fernandez de Sevilla D, Buno W. The muscarinic long-term enhancement of NMDA and AMPA receptor-mediated transmission at Schaffer collateral synapses develop through different intracellular mechanisms. J Neurosci 2010;30:11032-42.

26. Yamazaki Y, Jia Y, Niu R, Sumikawa K. Nicotine exposure in vivo induces long-lasting enhancement of NMDA receptor-mediated currents in the hippocampus. Eur J Neurosci 2006;23:1819-28.

27. Aramakis VB, Metherate R. Nicotine selectively enhances NMDA receptor-mediated synaptic transmission during postnatal development in sensory neocortex. $J$ Neurosci 1998;18:8485-95.

28. Shen JX, Yakel JL. Nicotinic acetylcholine receptor-mediated calcium signaling in the nervous system. Acta Pharmacol Sin 2009;30:673-80.

29. Andre JM, Leach PT, Gould TJ. Nicotine ameliorates NMDA receptor antagonist-induced deficits in contextual fear conditioning through high-affinity nicotinic acetylcholine receptors in the hippocampus. Neuropharmacology 2011;60:617-25. 
30. Takada-Takatori Y, Kume T, Sugimoto M, Katsuki H, Sugimoto H, Akaike A. Acetylcholinesterase inhibitors used in treatment of Alzheimer's disease prevent glutamate neurotoxicity via nicotinic acetylcholine receptors and phosphatidylinositol 3-kinase cascade. Neuropharmacology 2006;51:474-86.

31. Rubio-Perez JM, Morillas-Ruiz JM. A review: inflammatory process in Alzheimer's disease, role of cytokines. ScientificWorldJournal 2012;2012:756357.

32. Doens D, Fernandez PL. Microglia receptors and their implications in the response to amyloid beta for Alzheimer's disease pathogenesis. J Neuroinflammation 2014;11:48.

33. Yoshiyama Y, Kojima A, Ishikawa C, Arai K. Anti-inflammatory action of donepezil ameliorates tau pathology, synaptic loss, and neurodegeneration in a tauopathy mouse model. J Alzheimers Dis 2010;22:295-306

34. Hwang J, Hwang H, Lee HW, Suk K. Microglia signaling as a target of donepezil. Neuropharmacology 2010;58:1122-9.

35. Kim HG, Moon M, Choi JG, Park G, Kim AJ, Hur J, Lee KT, Oh MS. Donepezil inhibits the amyloid-beta oligomer-induced microglial activation in vitro and in vivo. Neurotoxicology 2014;40:23-32.

36. van Maanen MA, Vervoordeldonk MJ, Tak PP. The cholinergic anti-inflammatory pathway: towards innovative treatment of rheumatoid arthritis. Nat Rev Rheumatol 2009;5:229-32.

37. Ghia JE, Blennerhassett P, Kumar-Ondiveeran H, Verdu EF, Collins SM. The vagus nerve: a tonic inhibitory influence associated with inflammatory bowel disease in a murine model. Gastroenterology 2006;131:1122-30.

38. Song XM, Li JG, Wang YL, Hu ZF, Zhou Q, Du ZH, Jia BH. The protective effect of the cholinergic anti-inflammatory pathway against septic shock in rats. Shock 2008;30:468-72.

39. Leib C, Katus HA, Kaya Z. Cholinergic control of inflammation in cardiovascular diseases. Trends Cardiovasc Med 2013;23:46-51.

40. Pohanka M, Snopkova S, Havlickova K, Bostik P, Sinkorova Z, Fusek J, Kuca K, Pikula J. Macrophage-assisted inflammation and pharmacological regulation of the cholinergic anti-inflammatory pathway. Curr Med Chem 2011;18:539-51.

41. Ulloa $\mathrm{L}$. The vagus nerve and the nicotinic anti-inflammatory pathway. Nat Rev Drug Discov 2005;4:673-84.

42. Reale M, Iarlori $\mathrm{C}$, Gambi F, Feliciani $\mathrm{C}$, Isabella L, Gambi D. The acetylcholinesterase inhibitor, Donepezil, regulates a Th2 bias in Alzheimer's disease patients. Neuropharmacology 2006;50:606-13.

43. Takata K, Kitamura Y, Saeki M, Terada M, Kagitani S, Kitamura R, Fujikawa Y, Maelicke A, Tomimoto H, Taniguchi T, Shimohama S. Galantamine-induced amyloid-\{beta\} clearance mediated via stimulation of microglial nicotinic acetylcholine receptors. $J$ Biol Chem 2010;285:40180-91.

44. Conti E, Galimberti G, Tremolizzo L, Masetto A, Cereda D, Zanchi C, Piazza F, Casati M, Isella V, Appollonio I, Ferrarese C. Cholinesterase inhibitor use is associated with increased plasma levels of anti-Abeta 1-42 antibodies in Alzheimer's disease patients. Neurosci Lett 2010;486:193-6.

45. Lannfelt L, Relkin NR, Siemers ER. Amyloid-ss-directed immunotherapy for Alzheimer's disease. J Intern Med 2014;275:284-95

46. Fonnum F. Glutamate: a neurotransmitter in mammalian brain. J Neurochem 1984;42:1-11.

47. Bliss TV, Collingridge GL. A synaptic model of memory: long-term potentiation in the hippocampus. Nature 1993;361:31-9.

48. Ho VM, Lee JA, Martin KC. The cell biology of synaptic plasticity. Science 2011;334:623-8.

49. Morris RG. Long-term potentiation and memory. Philos Trans $R$ Soc Lond B Biol Sci 2003;358:643-7.

50. Jacob CP, Koutsilieri E, Bartl J, Neuen-Jacob E, Arzberger T, Zander N, Ravid R, Roggendorf W, Riederer P, Grunblatt E. Alterations in expression of glutamatergic transporters and receptors in sporadic Alzheimer's disease. J Alzheimers Dis 2007;11:97-116.

51. Brito-Moreira J, Paula-Lima AC, Bomfim TR, Oliveira FB, Sepulveda FJ, De Mello FG, Aguayo LG, Panizzutti R, Ferreira ST. Abeta oligomers induce glutamate release from hippocampal neurons. Curr Alzheimer Res 2011;8:552-62.

52. Lau A, Tymianski M. Glutamate receptors, neurotoxicity and neurodegeneration. Pflugers Arch 2010;460:525-42.

53. O'Shea SD, Smith IM, McCabe OM, Cronin MM, Walsh DM, O'Connor WT. Intracerebroventricular administration of amyloid b-protein oligomers selectively increases dorsal hippocampal dialysate glutamate levels in the awake rat. Sensors 2008;8:7428-37.

54. Rusakov DA, Harrison E, Stewart MG. Synapses in hippocampus occupy only $1-2 \%$ of cell membranes and are spaced less than half-micron apart: a quantitative ultrastructural analysis with discussion of physiological implications. Neuropharmacology 1998;37:513-21.

55. Papouin T, Oliet SH. Organization, control and function of extrasynaptic NMDA receptors. Philos Trans R Soc Lond B Biol Sci 2014;369:20130601

56. Leveille F, El Gaamouch F, Gouix E, Lecocq M, Lobner D, Nicole O, Buisson A. Neuronal viability is controlled by a functional relation between synaptic and extrasynaptic NMDA receptors. FASEB $J$ 2008:22:4258-71.

57. Mohs RC. The clinical syndrome of Alzheimer's disease: aspects particularly relevant to clinical trials. Genes Brain Behav 2005;4:129-33.

58. Lanari A, Amenta F, Silvestrelli G, Tomassoni D, Parnetti L. Neurotransmitter deficits in behavioural and psychological symptoms of Alzheimer's disease. Mech Ageing Dev 2006;127:158-65.

59. Cummings JL, Back C. The cholinergic hypothesis of neuropsychiatric symptoms in Alzheimer's disease. Am J Geriatr Psychiatry 1998;6:S64-78.

60. Minger SL, Esiri MM, McDonald B, Keene J, Carter J, Hope T, Francis PT. Cholinergic deficits contribute to behavioral disturbance in patients with dementia. Neurology 2000;55:1460-7.

61. Engelborghs S, Vloeberghs E, Le Bastard N, Van Buggenhout M, Marien P, Somers N, Nagels G, Pickut BA, De Deyn PP. The dopaminergic neurotransmitter system is associated with aggression and agitation in frontotemporal dementia. Neurochem Int 2008;52:1052-60.

62. Carrasco MM, Aguera L, Gil P, Morinigo A, Leon T. Safety and effectiveness of donepezil on behavioral symptoms in patients with Alzheimer disease. Alzheimer Dis Assoc Disord 2011;25:333-40.

63. Klyubin I, Wang Q, Reed MN, Irving EA, Upton N, Hofmeister J, Cleary JP, Anwyl R, Rowan MJ. Protection against Abeta-mediated rapid disruption of synaptic plasticity and memory by memantine. Neurobiol Aging 2011;32:614-23.

64. Saab BJ, Luca RM, Yuen WB, Saab AM, Roder JC. Memantine affects cognitive flexibility in the Morris water maze. $J$ Alzheimers Dis 2011;27:477-82.

65. Creeley C, Wozniak DF, Labruyere J, Taylor GT, Olney JW. Low doses of memantine disrupt memory in adult rats. $J$ Neurosci 2006;26:3923-32.

66. Neumeister KL, Riepe MW. Synergistic effects of antidementia drugs on spatial learning and recall in the APP23 transgenic mouse model of Alzheimer's disease. J Alzheimers Dis 2012;30:245-51.

67. Shearman E, Rossi S, Szasz B, Juranyi Z, Fallon S, Pomara N, Sershen H, Lajtha A. Changes in cerebral neurotransmitters and metabolites induced by acute donepezil and memantine administrations: a microdialysis study. Brain Res Bull 2006;69:204-13

68. Drever BD, Anderson WG, Johnson H, O'Callaghan M, Seo S, Choi DY, Riedel G, Platt B. Memantine acts as a cholinergic stimulant in the mouse hippocampus. J Alzheimers Dis 2007;12:319-33.

69. Aracava Y, Pereira EF, Maelicke A, Albuquerque EX. Memantine blocks alpha7* nicotinic acetylcholine receptors more potently than n-methyl-D-aspartate receptors in rat hippocampal neurons. $J$ Pharmacol Exp Ther 2005;312:1195-205.

70. Ihalainen J, Sarajarvi T, Rasmusson D, Kemppainen S, Keski-Rahkonen P, Lehtonen M, Banerjee PK, Semba K, Tanila H. Effects of memantine and donepezil on cortical and hippocampal acetylcholine levels and object recognition memory in rats. Neuropharmacology 2011;61:891-9.

71. Doody RS, Dunn JK, Clark CM, Farlow M, Foster NL, Liao T, 
Gonzales N, Lai E, Massman P. Chronic donepezil treatment is associated with slowed cognitive decline in Alzheimer's disease. Dement Geriatr Cogn Disord 2001;12:295-300.

72. Areosa SA, Sherriff F, McShane R. Memantine for dementia. Cochrane Database Syst Rev 2005;20:CD003154

73. Black SE, Doody R, Li H, McRae T, Jambor KM, Xu Y, Sun Y, Perdomo CA, Richardson S. Donepezil preserves cognition and global function in patients with severe Alzheimer disease. Neurology 2007;69:459-69.

74. Farlow M, Veloso F, Moline M, Yardley J, Brand-Schieber E, Bibbiani F, Zou H, Hsu T, Satlin A. Safety and tolerability of donepezil $23 \mathrm{mg}$ in moderate to severe Alzheimer's disease. BMC Neurol 2011;11:57.

75. Schulz JB, Rainer M, Klunemann HH, Kurz A, Wolf S, Sternberg K, Tennigkeit $\mathrm{F}$. Sustained effects of once-daily memantine treatment on cognition and functional communication skills in patients with moderate to severe Alzheimer's disease: results of a 16-week open-label trial. J Alzheimers Dis 2011;25:463-75.

76. Rainer M, Wuschitz A, Jagsch C, Erb C, Chirikdjian JJ, Mucke HA. Memantine in moderate to severe Alzheimer's disease: an observational post-marketing study. $J$ Neural Transm 2011;118:1255-9.

77. Gauthier S, Wirth Y, Mobius HJ. Effects of memantine on behavioural symptoms in Alzheimer's disease patients: an analysis of the Neuropsychiatric Inventory (NPI) data of two randomised, controlled studies. Int J Geriatr Psychiatry 2005;20:459-64.

78. Feldman H, Gauthier S, Hecker J, Vellas B, Subbiah P, Whalen E, Donepezil MSIG. A 24-week, randomized, double-blind study of donepezil in moderate to severe Alzheimer's disease. Neurology 2001;57:613-20.

79. Patel L, Grossberg GT. Combination therapy for Alzheimer's disease. Drugs Aging 2011;28:539-46.

80. Howard R, McShane R, Lindesay J, Ritchie C, Baldwin A, Barber R, Burns A, Dening T, Findlay D, Holmes C, Hughes A, Jacoby R, Jones R, Jones R, McKeith I, Macharouthu A, O’Brien J, Passmore P, Sheehan B, Juszczak E, Katona C, Hills R, Knapp M, Ballard C, Brown R, Banerjee S, Onions C, Griffin M, Adams J, Gray R, Johnson T, Bentham P, Phillips P. Donepezil and memantine for moderate-to-severe Alzheimer's disease. $N$ Engl J Med 2012;366:893-903. 